\title{
Effects of Electron Kinetic Energy and Ion-Electron Inelastic Collisions in Electron Capture Dissociation Measured Using Ion Nanocalorimetry
}

\author{
Jeremy T. O’Brien, James S. Prell, Anne I. S. Holm, ${ }^{*}$ and \\ Evan R. Williams \\ Department of Chemistry, University of California-Berkeley, Berkeley, California, USA
}

Ion nanocalorimetry is used to measure the effects of electron kinetic energy in electron capture dissociation (ECD). With ion nanocalorimetry, the internal energy deposited into a hydrated cluster upon activation can be determined from the number of water molecules that evaporate. Varying the heated cathode potential from -1.3 to $-2.0 \mathrm{~V}$ during ECD has no effect on the average number of water molecules lost from the reduced clusters of either $\left[\mathrm{Ca}\left(\mathrm{H}_{2} \mathrm{O}\right)_{15}\right]^{2+}$ or $\left[\mathrm{Ca}\left(\mathrm{H}_{2} \mathrm{O}\right)_{32}\right]^{2+}$, even when these data are extrapolated to a cathode potential of zero volts. These results indicate that the initial electron kinetic energy does not go into internal energy in these ions upon ECD. No effects of ion heating from inelastic ion-electron collisions are observed for electron irradiation times up to $200 \mathrm{~ms}$, although some heating occurs for $\left[\mathrm{Ca}\left(\mathrm{H}_{2} \mathrm{O}\right)_{17}\right]^{2+}$ at longer irradiation times. In contrast, this effect is negligible for $\left[\mathrm{Ca}\left(\mathrm{H}_{2} \mathrm{O}\right)_{32}\right]^{2+}$, a cluster size typically used in nanocalorimetry experiments, indicating that energy transfer from inelastic ion-electron collisions is negligible compared with effects of radiative absorption and emission for these larger clusters. These results have significance toward establishing the accuracy with which electrochemical redox potentials, measured on an absolute basis in the gas phase using ion nanocalorimetry, can be related to relative potentials measured in solution. (J Am Soc Mass Spectrom 2008, 19, 772-779) (C 2008 American Society for Mass Spectrometry

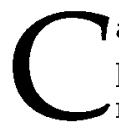

apture of an electron by a multiply charged protein can result in extensive backbone fragmentation from which information about the sequence [1-3], sites of posttranslational modifications [3-7], and even tertiary structure can be obtained $[2,8,9]$. Since the introduction of this electron capture dissociation (ECD) method by Zubarev and colleagues [1], who combined thermally generated electrons with trapped ions in a Fourier-transform ion cyclotron resonance (FT/ICR) mass spectrometer, others have demonstrated that similar fragmentation pathways can be obtained when the electron is captured from an atom [10,11] or from molecular anions $[12,13]$. These methods provide a new route to obtain structural information from intact proteins and large peptides, making applications such as "top-down" proteomics [7] feasible.

Ion-electron recombination or electron capture (EC) is exothermic by a value corresponding to the recombination energy (RE) [14, 15]. This energy can partition

Address reprint requests to Dr. Evan R. Williams, Department of Chemistry, University of California-Berkeley, Latimer Hall \#1460, Berkeley, CA 94720-1460. E-mail: williams@cchem.berkeley.edu

* A. I. S. Holm is a visiting graduate student from the University of Aarhus, Denmark.

All coauthors contributed substantially to this research. into internal modes of the precursor ion and into translational, rotational, and vibrational modes of the dissociation products. The extent of internal energy deposition upon ion activation can be measured using "chemical thermometers," which are ions that have fragmentation pathways with known activation energies and entropies. For example, Cooks and colleagues used $\mathrm{Fe}(\mathrm{CO})_{5}{ }^{+\cdot}$ to compare the energy deposition of collision-induced dissociation and surface-induced dissociation [16]. The appearance energies for fragments of $\mathrm{Fe}(\mathrm{CO})_{5}{ }^{+\cdot}$ are known and their formation occurs with similar entropies, so that the internal energy deposition is directly reflected by the fragment ion abundances. A measure of the internal energy deposition into molecular ions of $n$-butylbenzene molecules can be obtained from the relative abundance of fragment ions at $m / z 91$ and 92 [17-19]. The appearance potential of the former is higher, but so is the entropy, making it the favored process when more internal energy is deposited into the molecular ion. Rate constants can be measured using thermal activation methods, such as blackbody infrared radiative dissociation (BIRD) [20-23], and these values can be used to establish "effective" temperatures of ions activated by other methods [20]. 
We recently demonstrated that hydrated cluster ions are ideal "nanocalorimeters" that can be used to accurately measure the internal energy deposited into these ions upon activation [24-27]. This nanocalorimetry method has been used to measure the internal energy deposited by EC with thermally generated electrons as a function of cluster size and cation identity [24-27]. For sufficiently large hydrated clusters containing divalent or trivalent ions, EC results in loss of multiple water molecules from the reduced precursor. For example, EC by $\left[\mathrm{Ru}\left(\mathrm{NH}_{3}\right)_{6}\left(\mathrm{H}_{2} \mathrm{O}\right)_{55}\right]^{3+}$ results in formation of $\left[\mathrm{Ru}\left(\mathrm{NH}_{3}\right)_{6}\left(\mathrm{H}_{2} \mathrm{O}\right)_{n}\right]^{2+}, n=36,37$, and 38, corresponding to the loss of 17-19 water molecules from the reduced precursor ion [26]. For these large clusters, all the available recombination energy is deposited into internal modes of the ion and the dissociation is statistical. In contrast, dissociation of much smaller clusters in which loss of a hydrogen atom and water molecules occurs can be nonstatistical [25].

For large clusters where the dissociation is statistical, the RE can be obtained from the average number of water molecules lost from the reduced precursor. To obtain the RE, the threshold dissociation energy for the loss of each water molecule from the reduced precursor must be known. Values for clusters of the size typically investigated have not been measured, but these values can be obtained from the Thomson liquid drop model $[28,29]$. Various implementations of this model have been recently evaluated by comparison to experimental data for both monovalent and divalent ions [29]. A recently introduced discrete implementation of the Thomson model that takes into account ion size appears to accurately fit most experimental and quantum chemical data [29]. Energy can also partition into translational, rotational, and vibrational modes of each water molecule that is lost and can be accounted for using a simple statistical model. A more detailed description about how RE values can be accurately obtained from the number of water molecules lost, including effect of energy partitioning, is presented elsewhere [27].

Unlike some methods, such as photoionization spectroscopy, which can be used to obtain vertical ionization energies, the RE values obtained from this experiment are adiabatic values and correspond to the adiabatic ionization energy of the reduced precursor $[26,27]$. Although the initial electron capture may be a vertical process, solvent reorganization is fast (few picoseconds) compared with the timescale of these nanocalorimetry experiments (tens to hundreds of milliseconds). Energy released upon solvent reorganization will appear as internal energy in these clusters and is reflected by the number of water molecules that evaporate from the reduced clusters.

An emerging application of this nanocalorimetry method is measuring physical properties of ions in bulk solution that are difficult to obtain by other methods. For example, reduction potentials of redox active species in bulk solution are measured on a relative basis where the potential of one half-cell is measured relative to that of another. Such measurements result in a ladder of thermochemical values anchored to that of the standard hydrogen electrode, which is arbitrarily assigned a value of exactly $0 \mathrm{~V}$. We have recently reported the use of our ion nanocalorimetry method to obtain absolute solution-phase reduction potentials [26, 27]. By comparing these values to relative values measured in solution, an absolute value for the standard hydrogen potential of $4.2 \pm 0.4 \mathrm{~V}$ is obtained [27].

Many factors contribute to the ultimate accuracy of the nanocalorimetry method. Two important factors are the roles of the electron kinetic energy and ion-electron inelastic collisions on values of the RE obtained by ion nanocalorimetry. Here, we demonstrate that the internal energy deposited into hydrated clusters does not depend on the cathode voltage, which can be used to vary the electron kinetic energy, over the range of values typically used in an ECD experiment. In addition, we show that inelastic ion-electron collisions occur, but that these collisions do not significantly affect the internal energy deposition reported in these nanocalorimetry experiments under typical experimental conditions.

\section{Experimental}

Experiments were performed in a 2.75 Tesla FT/ICR mass spectrometer, equipped with a nanoelectrospray ion source [30], a temperature-controlled ion cell [31], and a heated metal cathode [25] (Figure 1). The cylindrical ion cell $(10 \mathrm{~cm}$ long $\times 7 \mathrm{~cm}$ in diameter $)$ consists of four copper mesh excite/detect plates separated from two beryllium-copper trapping plates by macor rings. The trapping plates are solid except for a central 1.0-cm hole and are wound with thin copper wire to ensure a uniform electric field across the hole. An oxygen-free copper jacket surrounds the cell and a controlled flow of liquid nitrogen is introduced into the copper jacket by means of a solenoid regulated by a temperature controller (Model No. CN-i3222, Omega Engineering, Inc., Stamford, CT, USA). The cell is allowed to equilibrate to a temperature of $-140.0^{\circ} \mathrm{C}$ for at least $8 \mathrm{~h}$ before conducting these experiments.

The nanoelectrospray ion source, with which extensively hydrated ion clusters are generated, is described in detail elsewhere [30]. Briefly, borosilicate capillaries with tips pulled to an inner diameter of about $1 \mu \mathrm{m}$ are filled with $4 \mathrm{mM}$ aqueous solution of calcium chloride (Fisher Scientific, Fair Lawn, NJ, USA). A platinum wire is placed in direct contact with the solution and held at a potential of about $450 \mathrm{~V}$ relative to the approximately $90^{\circ} \mathrm{C}$ heated metal capillary entrance to the mass spectrometer. Ions are guided through five stages of differential pumping and trapped in the ion cell. A 7-s pulse of nitrogen gas, which raises the cell pressure to about $5 \times 10^{-7}$ Torr, is used to assist in trapping and thermalizing the ions. A mechanical shutter is closed at all other times to prevent additional ions from entering the cell. The trapped ions are allowed to reach a steady- 


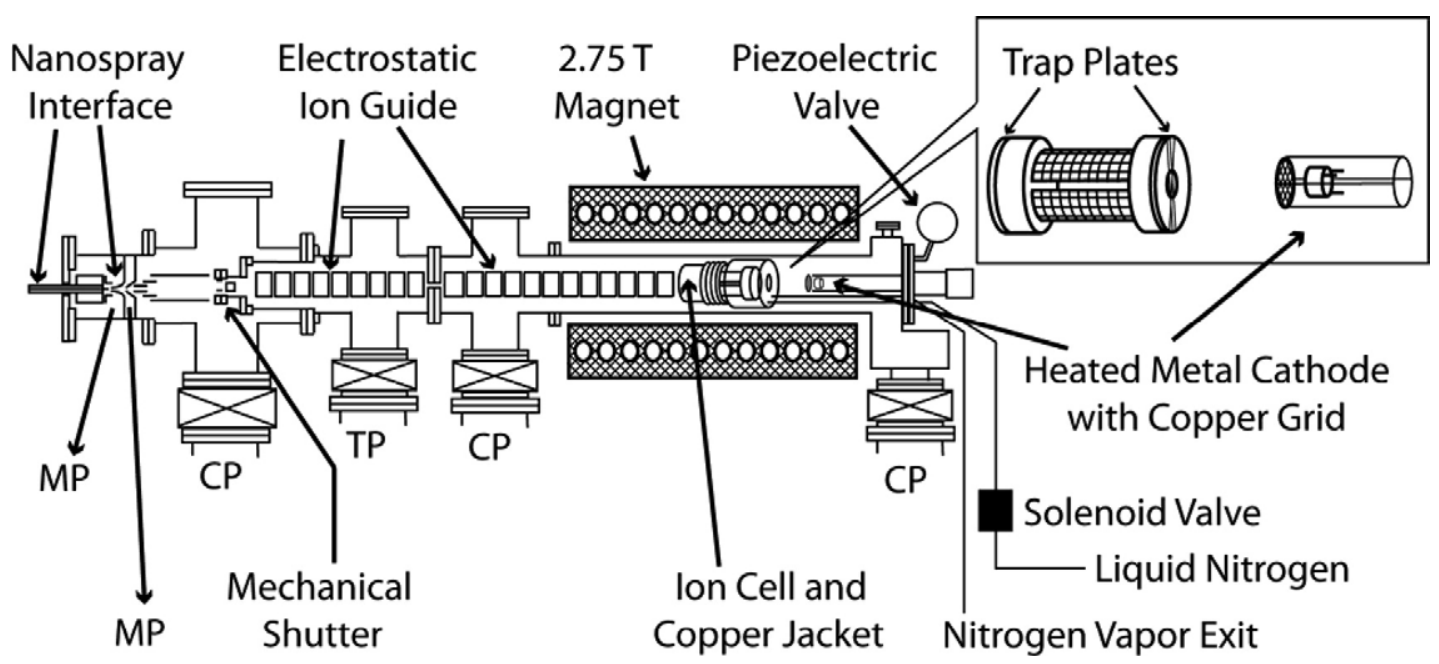

Figure 1. Schematic of the $2.75 \mathrm{~T} \mathrm{FT/ICR} \mathrm{mass} \mathrm{spectrometer} \mathrm{used} \mathrm{in} \mathrm{these} \mathrm{experiments.} \mathrm{The} \mathrm{inset}$ shows details of the ion cell and heated metal cathode with copper grid. The heated metal cathode is mounted on the central axis of the vacuum chamber and is positioned $20 \mathrm{~cm}$ from the center of the ion cell. MP, CP, and TP indicate mechanical pump, cryopump, and turbopump, respectively.

state internal energy distribution by exchange of photons with the blackbody radiation field inside the cell [21-23] over a period of $8 \mathrm{~s}$, during which time the cell pressure returns to $<10^{-8}$ Torr. Except where noted, the trapping plate potentials were held at $8.5 \mathrm{~V}$ (source side) and $9.5 \mathrm{~V}$ (far side) during ion accumulation, stepped down gradually during the 8-s delay to $2.0 \mathrm{~V}$, and held at this potential for the remainder of the experimental sequence.

Clusters of interest are isolated using stored waveform inverse Fourier transforms (SWIFTs), followed by a 50-ms delay. This is followed by either electron irradiation or BIRD. Electrons are thermally generated using a 1.0-cm-diameter barium scandate-impregnated cathode (HeatWave Laboratories, Watsonville, CA, USA) mounted axially $20 \mathrm{~cm}$ away from the cell center. A direct current of $3 \mathrm{~A}$ is used to heat the cathode to a temperature of about $950{ }^{\circ} \mathrm{C}$. To introduce electrons into the cell, the potential of the cathode housing is pulsed from $+10.0 \mathrm{~V}$ to values between 0.0 and $-10.0 \mathrm{~V}$. A value of $-1.5 \mathrm{~V}$ for the cathode potential during electron irradiation resulted in maximum ECD efficiency, and this setting was used in all experiments where cathode potential was not a variable. Electrons that pass through the cell should be reflected back through the cell due to the ion-injection optics that are maintained at high negative potentials [22]. For BIRD experiments, the heated cathode potential was kept at $+10.0 \mathrm{~V}$ to prevent electrons from entering the cell. In all experiments, a potential of $+9 \mathrm{~V}$ was applied to a copper-wire mesh mounted $0.5 \mathrm{~cm}$ in front of the cathode. All potentials are referenced to instrumental ground.

A mobile instrumentation data acquisition system (MIDAS) [32] was used to acquire 32K data point transients. Ion abundances were obtained by subtracting the average noise in an approximately $30 \mathrm{~m} / \mathrm{z}$ signal-free region near the precursor. For ECD experi- ments, the average number of water molecules lost from a cluster upon reduction was calculated as the weighted average of reduced product cluster abundances and corrected for background dissociation from BIRD by subtracting the water loss due to BIRD, as measured with no electrons present in the cell. Experimental error was propagated assuming a distribution of noise that is uniform and uncorrelated with respect to $\mathrm{m} / \mathrm{z}$ in the mass spectral regions investigated, and normal with respect to intensity. The standard deviation in noise intensity over the aforementioned signalfree region was propagated through all calculations to estimate error.

\section{Results and Discussion}

\section{Electron Kinetic Energy}

In these ECD experiments, the electron kinetic energy is poorly defined and depends on a number of experiment parameters including, for example, position inside the ion cell; trapping plate potentials; cell geometry; cathode voltage, temperature, and location; and electron current. Electrons produced from the heated cathode should have an initial velocity spread given by a Maxwell-Boltzmann distribution at the cathode temperature. At $950^{\circ} \mathrm{C}$, the temperature of the heated cathode in these experiments, the average electron velocity is $1.9 \times$ $10^{5} \mathrm{~m} / \mathrm{s}$, corresponding to a kinetic energy of $0.1 \mathrm{eV}$. In addition to the thermal distribution, electron-electron repulsion at the high electron currents typically used in these experiments will result in an even broader distribution of electron kinetic energies.

To study possible effects of electron kinetic energy on the internal energy deposition into ions upon EC, the potential of the cathode can be varied while keeping all other parameters constant. However, there is a limited range over which the cathode potential can be varied 


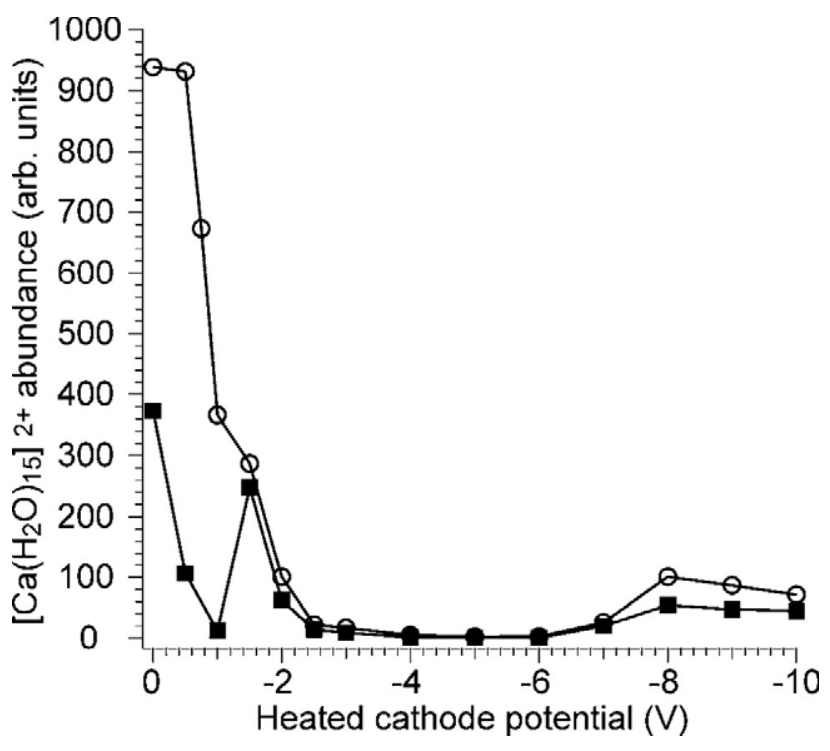

Figure 2. $\left[\mathrm{Ca}\left(\mathrm{H}_{2} \mathrm{O}\right)_{15}\right]^{2+}$ precursor abundance after $120 \mathrm{~ms}$ of electron irradiation as a function of heated cathode potential, measured with two different trapping plate potential conditions: a symmetric $2.0 \mathrm{~V}$ trap potential during electron irradiation and ion detection (solid squares) and asymmetrical 8.3/9.2 V source-side/ far-side trap potentials during electron irradiation, $2.0 \mathrm{~V}$ during ion detection (open circles).

(about -1.2 to $-2.0 \mathrm{~V}$ in these experiments) and ECD products observed. To investigate the origin of this effect, $\left[\mathrm{Ca}\left(\mathrm{H}_{2} \mathrm{O}\right)_{15}\right]^{2+}$ was isolated in the cell and the precursor abundance was measured as a function of cathode potential with electron irradiation times of 120 ms (Figure 2). With symmetric trapping potentials of $2.0 \mathrm{~V}$ during ECD and ion detection, rapid loss of the precursor is observed when the cathode potential is varied from 0 to $-1.0 \mathrm{~V}$ (Figure 2; solid black squares). A local maximum in precursor intensity occurs at about $-1.5 \mathrm{~V}$ and the precursor intensity rapidly decreases at cathode potentials more negative than $-2.0 \mathrm{~V}$. Another local maximum in precursor intensity is observed at $-8.0 \mathrm{~V}$. To investigate effects of trapping plate potentials on this phenomenon, asymmetric trapping potentials of 8.3 and $9.2 \mathrm{~V}$ were used during ECD $(2.0 \mathrm{~V}$ during ion detection). With these higher trap potentials, precursor ion loss is significantly reduced at low cathode potentials, but otherwise the trapping potentials during ECD have little effect (Figure 2; open circles). Similar results to the higher trapping plate data have been reported by Lioe and $\mathrm{O}^{\prime}$ Hair, who irradiated singly charged ions with electrons and concluded that the loss of signal was due to neutralization [33]. However, no singly charged ions were observed in our experiments with cathode potentials between -3.0 and $-7.0 \mathrm{~V}$, indicating that ion-electron recombination is not the origin of precursor loss. Marshall and colleagues demonstrated that manipulation of the trapping potentials during and immediately after the ECD event or the use of single-pass versus reflected-electron configurations can shift the peak in ECD efficiency as a function of cathode potential [34]. High electron currents can reduce the effective potential inside the cell, which could result in loss of positively charged ions, consistent with retention of ion signal with high trap potentials when the cathode potential is low. However, the maximum observed at $-1.5 \mathrm{~V}$ with $2.0-\mathrm{V}$ trap potentials suggests that other effects, such as inelastic or elastic collisions with electrons which could "push" the ions out of the cell, may occur.

\section{Effects of Cathode Potential on ECD Spectra}

To determine how the electron kinetic energy affects the internal energy deposition upon EC, ECD spectra of $\left[\mathrm{Ca}\left(\mathrm{H}_{2} \mathrm{O}\right)_{32}\right]^{2+}$ and $\left[\mathrm{Ca}\left(\mathrm{H}_{2} \mathrm{O}\right)_{15}\right]^{2+}$ were measured as a function of cathode potential. ECD of the former results exclusively in loss of either 10 or 11 water molecules from the reduced precursor, whereas ECD of the latter results in loss of an $\mathrm{H}$ atom and 8 or 9 water molecules, resulting in formation of hydrated calcium hydroxide with a single charge. For $\left[\mathrm{Ca}\left(\mathrm{H}_{2} \mathrm{O}\right)_{32}\right]^{2+}$, there is no discernable trend in the average number of water molecules lost from the reduced precursor for cathode potentials ranging from -1.2 to $-2.0 \mathrm{~V}$ (Figure 3). The average number of water molecules lost over this range is $10.26 \pm 0.04$. Extrapolation of these data to a cathode housing potential of $0.0 \mathrm{~V}$ results in a value of $10.2 \pm 0.2$ water molecules. If the electron kinetic energy were deposited into internal modes of the ion, the ECD spectra should reflect a $0.80-\mathrm{eV}(18.4 \mathrm{kcal} / \mathrm{mol})$ change in internal energy deposition over this $0.80-\mathrm{V}$ range of cathode potentials. Because approximately $0.4 \mathrm{eV}(\sim 9 \mathrm{kcal} / \mathrm{mol})$ is required to evaporate a water molecule from a monovalent cluster of this size [29], if the entire electron kinetic energy had been deposited into the ion, the average

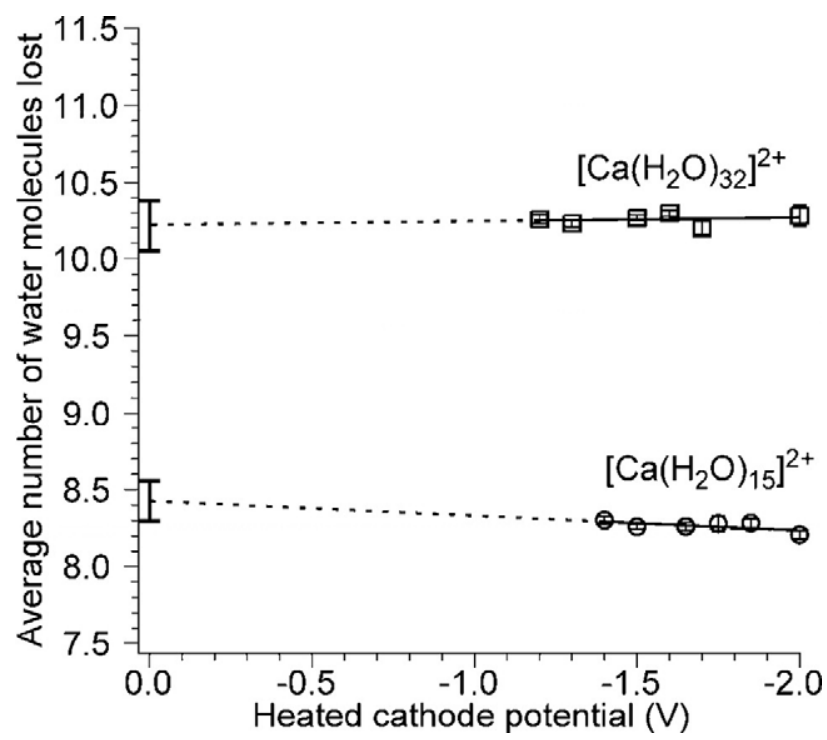

Figure 3. Average number of water molecules lost upon reduction of $\left[\mathrm{Ca}\left(\mathrm{H}_{2} \mathrm{O}\right)_{15}\right]^{2+}$ and $\left[\mathrm{Ca}\left(\mathrm{H}_{2} \mathrm{O}\right)_{32}\right]^{2+}$ as a function of heated cathode potential. Dashed lines indicate extrapolated leastsquares fits of the data, and the error bars at $0.0 \mathrm{~V}$ indicate the propagated error in the intercept. 
number of water molecules that evaporate from these clusters should have changed by roughly $0.80 / 0.4=2.0$ water molecules over the $0.80-\mathrm{V}$ range in cathode potentials. The insensitivity of the ECD spectra to cathode voltage clearly indicates that the internal energy deposited into these hydrated clusters is not a function of the electron kinetic energy over the range of cathode potentials typically used in ECD experiments.

Similar results are obtained for $\left[\mathrm{Ca}\left(\mathrm{H}_{2} \mathrm{O}\right)_{15}\right]^{2+}$ where, again, there is no discernable trend in the average number of water molecules lost as a function of the cathode housing potential over a range of -1.4 to $-2.0 \mathrm{~V}$ with an average value of $8.26 \pm 0.04$ (Figure 3). Extrapolation of these data to a cathode potential of $0.0 \mathrm{~V}$ results in a value of $8.4 \pm 0.1$. As was the case for $\left[\mathrm{Ca}\left(\mathrm{H}_{2} \mathrm{O}\right)_{32}\right]^{2+}$, the cathode potential and thus initial electron kinetic energy have no effect on the internal energy deposited into this ion. Zubarev et al. reported that the fragmentation patterns in ECD spectra of $11+$ ubiquitin ions did not change over a $0.0-$ to $-0.4-\mathrm{V}$ range of cathode potentials and concluded that the electron kinetic energy was minor compared to the energy released upon EC [35]. Our results show that changing cathode potentials does not affect ECD energy deposition in the low electron energy regime. However, different fragment ions have been observed in "hot" ECD experiments where the electron kinetic energy is $>5 \mathrm{eV}[36,37]$.

Trapping plate potentials during ECD also influence the electron kinetic energy inside the ion cell. To investigate the effects of trap potentials in these experiments, an ECD spectrum of $\left[\mathrm{Ca}\left(\mathrm{H}_{2} \mathrm{O}\right)_{32}\right]^{2+}$ was measured using asymmetric trap potentials of 8.3 and $9.2 \mathrm{~V}$ (source side and far side, respectively) during ECD. An average of $10.25 \pm 0.01$ water molecules is lost from the reduced precursor, essentially the same number observed when the spectrum was acquired with a symmetric trapping potential of $2.0 \mathrm{~V}$. These results indicate that the trapping potentials do not influence the internal energy deposited into ions upon ECD over the range of values typically used in these experiments.

Although these results may seem counterintuitive, it is important to consider that the capture of an electron is most efficient when the relative velocity between an ion and an electron is zero. The relative velocities of positive ions and electrons can be carefully controlled by merging the corresponding ion beams in ion storage rings [38-41]. From such experiments, accurate recombination cross sections as a function of relative ionelectron velocity can be obtained. The cross section for dissociative recombination when a protonated water molecule captures an electron increases by about 5 orders of magnitude as the center-of-mass kinetic energy decreases from 30 to $0.001 \mathrm{eV} \mathrm{[40].} \mathrm{The} \mathrm{EC} \mathrm{cross}$ section for $\mathrm{D}^{+}\left(\mathrm{D}_{2} \mathrm{O}\right)_{2}$ increases by about 3 orders of magnitude when the ion-electron center-of-mass kinetic energy decreases from 0.01 to $0.001 \mathrm{eV}$ [41].

In the ECD experiments described here, the spread of electron velocities is very broad. Contributing further to the broadening is electron-electron repulsion, which is significant at the high electron currents used in these experiments. In addition, inelastic ion-electron collisions that do not result in electron capture can result in lower electron kinetic energies. All of these factors could result in a small fraction of electrons with nearzero kinetic energies inside the ion cell, and these electrons should be the most efficiently captured by the slow moving positive ions in our experiment.

\section{Effects of Inelastic Ion-Electron Collisions on ECD Spectra}

Inelastic ion-electron collisions can deposit energy into either the intact precursor or the fragment ions, resulting in ion heating that could contribute to the extent of dissociation observed. A method to fragment organic ions based on this phenomenon has been implemented previously in FT/ICR mass spectrometers by Freiser and Beauchamp [42] and has been affectionately called electron impact excitation of ions from organics, or E-I-E-I-O [43]. This method has been used to dissociate singly charged peptides [33,44].

To investigate the extent to which inelastic ionelectron collisions occur and influence the internal energy deposition in these experiments, $\left[\mathrm{Ca}\left(\mathrm{H}_{2} \mathrm{O}\right)_{15}\right]^{2+}$ was isolated and ECD experiments were performed as a function of electron irradiation time from 40 to $200 \mathrm{~ms}$ with a cathode potential of $-1.5 \mathrm{~V}$. These data are corrected for contributions to ion heating by BIRD originating from the heated cathode and the cooled cell and surroundings. The average number of water molecules lost from the reduced precursor as a function of electron irradiation time is shown in Figure 4. There is

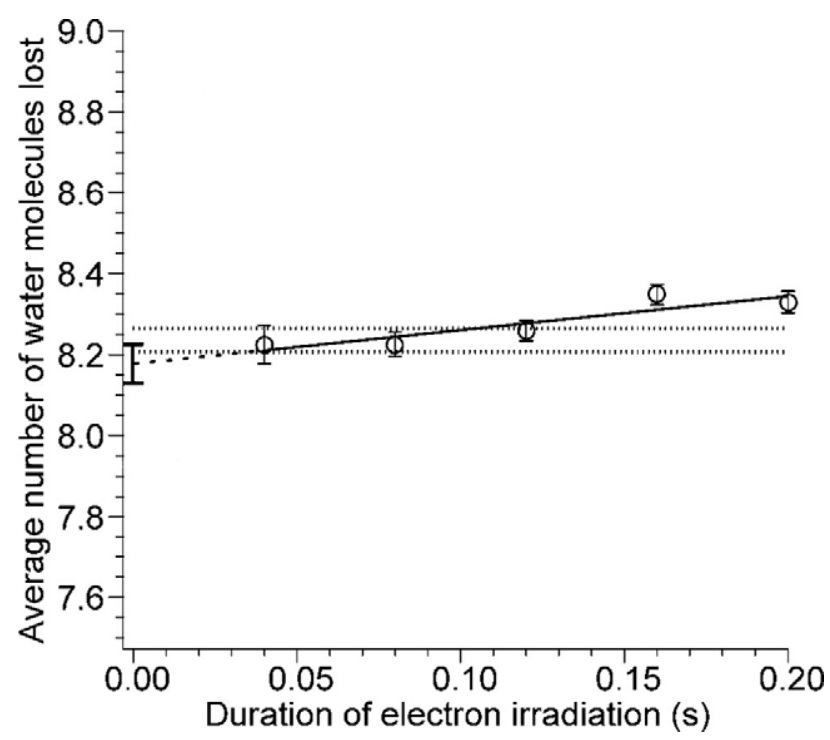

Figure 4. Average number of water molecules lost from reduced $\left[\mathrm{Ca}\left(\mathrm{H}_{2} \mathrm{O}\right)_{15}\right]^{2+}$ due to $\mathrm{EC}$ as a function of electron irradiation time. The dashed line indicates the extrapolated least-squares fit to the data and the error bars at $0.0 \mathrm{~s}$ indicate the propagated error in the intercept. The dotted lines represent one standard deviation above and below the average value of the data at 40, 80, and $120 \mathrm{~ms}$. 
a slight trend in the average number of water molecules lost as a function of electron irradiation time. Average numbers of water molecules lost at 40-, 80-, and 120-ms irradiation times are indistinguishable within experimental error; the average of these three values is $8.24 \pm$ 0.03 . Values at 160 and $200 \mathrm{~ms}$ are slightly higher and outside experimental error, indicating that inelastic ion-electron collisions do play a minor role in ion heating at these longer irradiation times. Extrapolation of these data to zero irradiation time should give the number of water molecules lost solely due to EC in the absence of any heating from inelastic ion-electron collisions; this value is $8.18 \pm 0.05$. From these results, we conclude that, although inelastic ion-electron collisions occur, they contribute negligibly to the internal energy of the ions when the electron irradiation is less than 120 ms. At longer irradiation times, this effect can be measured but continues to be negligible at least up to $200 \mathrm{~ms}$.

\section{Effects of Inelastic Ion-Electron Collisions on Precursor Heating}

In separate experiments, effects of precursor heating due to inelastic ion-electron collisions were obtained for both $\left[\mathrm{Ca}\left(\mathrm{H}_{2} \mathrm{O}\right)_{17}\right]^{2+}$ and $\left[\mathrm{Ca}\left(\mathrm{H}_{2} \mathrm{O}\right)_{32}\right]^{2+}$ by measuring the extent of water loss from the precursor ions as a function of electron irradiation time. For both ions, loss of one or two water molecules from the precursor constitute the only products observed in addition to singly charged product ions due to ECD. In these experiments, blackbody infrared radiative dissociation occurs [21-23] that can be directly attributed to the heated cathode that is located $20 \mathrm{~cm}$ away from the cell center [25]. Effects of precursor ion heating due to inelastic ion-electron collisions can be obtained from differences in the extent of water loss with and without electrons introduced into the cell. To do this, the cathode remains at about $950{ }^{\circ} \mathrm{C}$ in both experiments, but for the blackbody comparison, the cathode potential is $+10.0 \mathrm{~V}$ at all times so that no electrons enter the cell. Differences in the water loss from the precursor ion measured in these two experiments can be directly attributed to inelastic electron-ion collisions. The water loss from the precursor ions, corrected for loss of the precursor due to ECD, as a function of electron irradiation time is shown in Figure 5. For $\left[\mathrm{Ca}\left(\mathrm{H}_{2} \mathrm{O}\right)_{17}\right]^{2+}$, there is no significant difference in the fragmentation rate with or without electron irradiation up to $200 \mathrm{~ms}$, but at longer times, more fragmentation occurs when electrons are introduced into the ion cell (Figure 5a). This outcome indicates that inelastic ion-electron collisions result in heating of the precursor ion over this longer time frame. The induction period at times below about $200 \mathrm{~ms}$ indicates that the precursor ions require some initial heating to a steady-state temperature before pseudo-first-order kinetics are observed, analogous to preheating in laser dissociation kinetic studies [45].

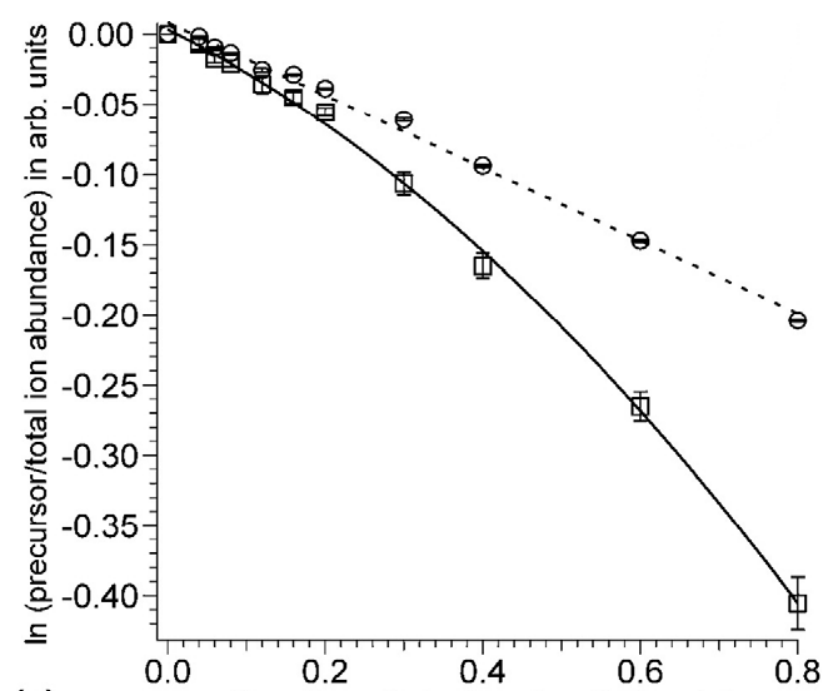

(a) Duration of electron irradiation (s)

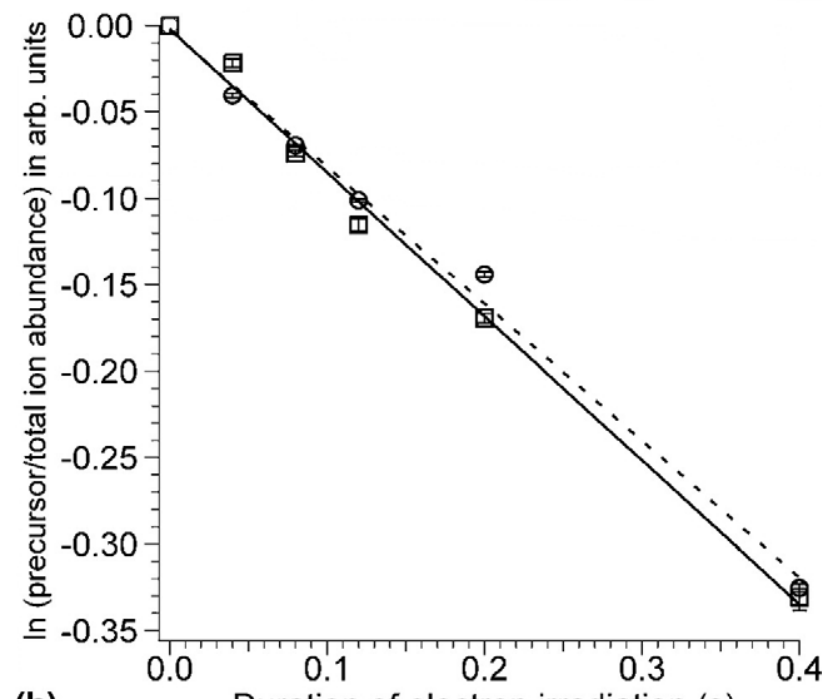

(b) Duration of electron irradiation (s)

Figure 5. Dissociation kinetics of (a) $\left[\mathrm{Ca}\left(\mathrm{H}_{2} \mathrm{O}\right)_{17}\right]^{2+}$ and (b) $\left[\mathrm{Ca}\left(\mathrm{H}_{2} \mathrm{O}\right)_{32}\right]^{2+}$ with (squares, cathode potential $-1.5 \mathrm{~V}$ ) and without (circles, cathode potential $+10.0 \mathrm{~V}$ ) electron irradiation as a function of electron irradiation time. The dashed lines are least-squares fits to the data obtained with the heated cathode potential at $+10.0 \mathrm{~V}$; the solid lines are a parabolic $\left(\left[\mathrm{Ca}\left(\mathrm{H}_{2} \mathrm{O}\right)_{17}\right]^{2+}\right)$ and least-squares fit $\left(\left[\mathrm{Ca}\left(\mathrm{H}_{2} \mathrm{O}\right)_{32}\right]^{2+}\right)$ to the data with a heated cathode potential of $-1.5 \mathrm{~V}$.

In contrast, there is no observable effect of inelastic ionelectron collisions for $\left[\mathrm{Ca}\left(\mathrm{H}_{2} \mathrm{O}\right)_{32}\right]^{2+}$ (Figure $5 b$ ) for times up to $400 \mathrm{~ms}$. In these experiments, the initial internal energy of this larger cluster is approximately twice that of the smaller cluster as are the rates of radiative absorption and emission. However, the threshold dissociation energies for loss of a water molecule from these two different size clusters are nearly the same. These experiments indicate that the rate of ion heating due to inelastic ion-electron collisions is negligible compared to that from radiative absorption (and emission) at this cluster size. Thus, for the cluster sizes typically used in nanocalorimetry ex- 
periments, heating of the ions due to inelastic ionelectron collisions is negligible under typical experimental conditions.

\section{Conclusions}

Ion nanocalorimetry is an accurate and highly sensitive method for measuring how much internal energy is deposited into ions upon activation [24-27]. This method has been recently applied to measuring absolute reduction potentials of redox couples in bulk solution [26, 27]. To improve the accuracy with which these values can be obtained, effects of electron kinetic energy and inelastic ion-electron collisions on the internal energy deposition in ECD must be known. In typical ECD experiments done in FT/ICR mass spectrometry, the relative kinetic energies of the electrons generated by heated metal cathodes and the trapped ions vary over a relatively wide range and are poorly defined. The kinetic energy of electrons in these ECD experiments can be precisely varied by changing the heated cathode potential. Under typical experimental conditions, varying the cathode potential has no measurable effect on the internal energy deposited into ions that capture electrons. These results are consistent with the presence of some small fraction of electrons with nearzero kinetic energy inside the cell. Such low-energy electrons can be produced by effects of electron-electron repulsion in the high-density electron beam and/or by inelastic ion-electron collisions that occur inside the ion cell. Capture cross sections for EC are significantly higher when the relative ion-electron velocity approaches zero, and it is capture of this small population of low-energy electrons that results in the observed ECD. These results may explain in part the poor absolute cross section for ion-electron recombination in these experiments.

With electron irradiation times up to $200 \mathrm{~ms}$, no discernable effects of inelastic ion-electron collisions are observed. At longer irradiation times, some ion heating due to inelastic ion-electron collisions is measurable for small nanoclusters, although this effect is negligible for the larger size clusters typically used in nanocalorimetry experiments. These results indicate that the cathode potential, trapping plate potential, and inelastic ion-electron collisions do not play a significant role in the internal energy deposition in ECD under typical experimental conditions.

\section{Acknowledgments}

We thank Professor Roman A. Zubarev for his pioneering contributions to the field of electron capture dissociation. We also acknowledge Matthew F. Bush, William A. Donald, and Ryan D. Leib for helpful discussions. This work was supported by National Science Foundation Grant CHE-0718790, National Institute of General Medical Services Grant R01 GM064712, and the European Project ITS-LEIF Grant RII 3/02 6016 to A. I. S. Holm.

\section{References}

1. Zubarev, R. A.; Kelleher, N. L.; McLafferty, F. W. Electron Capture Dissociation of Multiply Charged Protein Cations. A Nonergodic Process. J. Am. Chem. Soc. 1998, 120, 3265-3266.

2. Breuker, K.; Oh, H. B.; Horn, D. M.; Cerda, B. A.; McLafferty, F. W. Detailed Unfolding and Folding of Gaseous Ubiquitin Ions Characterized by Electron Capture Dissociation. J. Am. Chem. Soc. 2002, 124, 6407-6420.

3. Stensballe, A.; Jensen, O. N.; Olsen, J. V.; Haselmann, K. F.; Zubarev, R. A. Electron Capture Dissociation of Singly and Multiply Phosphorylated Peptides. Rapid Commun. Mass Spectrom. 2000, 14, 1793-1800.

4. Mirgorodskaya, E.; Roepstorff, P.; Zubarev, R. A. Localization of O-Glycosylation Sites in Peptides by Electron Capture Dissociation in a Fourier Transform Mass Spectrometer. Anal. Chem. 1999, 71, 4431-4436.

5. Sze, S. K.; Ge, Y.; Oh, H. B.; McLafferty, F. W. Top-Down Mass Spectrometry of a 29-kDa Protein for Characterization of Any Posttranslational Modification to Within One Residue. Proc. Natl. Acad. Sci. U.S.A 2002, 99, 1774-1779.

6. Kelleher, N. L.; Zubarev, R. A.; Bush, K.; Furie, B.; Furie, B. C.; McLafferty, F. W.; Walsh, C. T. Localization of Labile Posttranslational Modifications by Electron Capture Dissociation: The Case of gammaCarboxyglutamic Acid. Anal. Chem. 1999, 71, 4250-4253.

7. Ge, Y.; Lawhorn, B. G.; El Naggar, M.; Strauss, E.; Park, J. H.; Begley, T. P.; McLafferty, F. W. Top Down Characterization of Larger Proteins (45 kDa) by Electron Capture Dissociation Mass Spectrometry. J. Am. Chem. Soc. 2002, 124, 672-678.

8. Robinson, E. W.; Leib, R. D.; Williams, E. R. The Role of Conformation on Electron Capture Dissociation of Ubiquitin. J. Am. Soc. Mass Spectrom. 2006, 17, 1469-1479.

9. Breuker, K.; Oh, H. B.; Lin, C.; Carpenter, B. K.; McLafferty, F. W. Nonergodic and Conformational Control of the Electron Capture Dissociation of Protein Cations. Proc. Natl. Acad. Sci. U.S.A. 2004, 101, 14011-14016.

10. Hvelplund, P.; Liu, B.; Nielsen, S. B.; Tomita, S. Electron Capture Induced Dissociation of Peptide Dications. Int. J. Mass Spectrom. 2003, 225, 83-87.

11. Hvelplund, P.; Liu, B.; Nielsen, S. B.; Tomita, S.; Cederquist, H.; Jensen, J.; Schmidt, H. T.; Zettergren, H. Electron Capture and Loss by Protonated Peptides and Proteins in Collisions with $\mathrm{C}_{60}$ and Na. Eur. Phys. J. D 2003, 22, 75-79.

12. Coon, J. J.; Shabanowitz, J.; Hunt, D. F.; Syka, J. E. P. Electron Transfer Dissociation of Peptide Anions. J. Am. Soc. Mass Spectrom. 2005, 16, $880-882$.

13. Syka, J. E. P.; Coon, J. J.; Schroeder, M. J.; Shabanowitz, J.; Hunt, D. F. Peptide and Protein Sequence Analysis by Electron Transfer Dissociation Mass Spectrometry. Proc. Natl. Acad. Sci. U.S.A. 2004, 101, 9528 9533.

14. Iavarone, A. T.; Paech, K.; Williams, E. R. Effects of Charge State and Cationizing Agent on the Electron Capture Dissociation of a Peptide. Anal. Chem. 2004, 76, 2231-2238.

15. Zubarev, R. A. Reactions of Polypeptide Ions with Electrons in the Gas Phase. Mass Spectrom. Rev. 2003, 22, 57-77.

16. Dekrey, M. J.; Kenttämaa, H. I.; Wysocki, V. H.; Cooks, R. G. Energy Deposition in $\mathrm{Fe}(\mathrm{Co})_{5}{ }^{+}$' upon Collision with a Metal-Surface. Org. Mass Spectrom. 1986, 21, 193-195.

17. Griffiths, I. W.; Harris, F. M.; Mukhtar, E. S.; Beynon, J. H. Calculation of the Abundance Ratio $\left[91^{+} / 92^{+}\right]$from $n$-Butylbenzene Molecular-Ions as a Function of Internal Energy. Int. J. Mass Spectrom. Ion Process. 1981, $41,83-88$.

18. Baer, T.; Dutuit, O.; Mestdagh, H.; Rolando, C. Dissociation Dynamics of $n$-Butylbenzene Ions-The Competitive Production of $\mathrm{m} / \mathrm{z}$ 91-Fragment and 92-Fragment Ions. J. Phys. Chem. 1988, 92, 56745679.

19. Chen, J. H.; Hays, J. D.; Dunbar, R. C. Competitive 2-Channel Photodissociation of $n$-Butylbenzene Ions in the Fourier-Transform IonCyclotron Resonance Mass-Spectrometer. J. Phys. Chem. 1984, 88, 47594764

20. Schnier, P. D.; Jurchen, J. C.; Williams, E. R. The Effective Temperature of Peptide Ions Dissociated by Sustained Off-Resonance Irradiation Collisional Activation in Fourier Transform Mass Spectrometry. J. Phys. Chem. B 1999, 103, 737-745.

21. Price, W. D.; Schnier, P. D.; Jockusch, R. A.; Strittmatter, E. F.; Williams, E. R. Unimolecular Reaction Kinetics in the High-Pressure Limit Without Collisions. J. Am. Chem. Soc. 1996, 118, 10640-10644.

22. Price, W. D.; Schnier, P. D.; Williams, E. R. Tandem Mass Spectrometry of Large Biomolecule Ions by Blackbody Infrared Radiative Dissociation. Anal. Chem. 1996, 68, 859-866.

23. Price, W. D.; Williams, E. R. Activation of Peptide Ions by Blackbody Radiation: Factors That Lead to Dissociation Kinetics in the Rapid Energy Exchange Limit. J. Phys. Chem. A 1997, 101, 8844-8852.

24. Leib, R. D.; Donald, W. A.; O'Brien, J. T.; Bush, M. F.; Williams, E. R. Internal Energy Deposition in Electron Capture Dissociation Measured Using Hydrated Divalent Metal Ions as Nanocalorimeters. J. Am. Chem. Soc. 2007, 129, 4894-4895.

25. Leib, R. D.; Donald, W. A.; Bush, M. F.; O’Brien, J. T.; Williams, E. R. Nonergodicity in Electron Capture Dissociation Investigated Using Hydrated Ion Nanocalorimetry. J. Am. Soc. Mass Spectrom. 2007, 18, 1217-1231. 
26. Leib, R. D.; Donald, W. A.; O'Brien, J. T.; Bush, M. F.; Williams, E. R. Reduction Energy of $1 \mathrm{M}$ Aqueous Ruthenium(III) Hexaammine in the Gas Phase: A Route Toward Establishing an Absolute Electrochemical Scale. J. Am. Chem. Soc. 2007, 129, 7716-7717.

27. Donald, W. A.; Leib, R. D.; O'Brien, J. T.; Bush, M. F.; Williams, E. R. The Absolute Standard Hydrogen Electrode Potential Measured by Reduction of Aqueous Nanodrops in the Gas Phase. J. Am. Chem. Soc. 2008, 130, 3371-3381.

28. Holland, P. M.; Castleman, A. W. Thomson Equation Revisited in Light of Ion-Clustering Experiments. J. Phys. Chem. 1982, 86, 4181-4188.

29. Donald, W. A.; Williams, E. R. Evaluation of Different Implementations of the Thomson Liquid Drop Model: Comparison to Monovalent and Divalent Cluster Ion Experimental Data. J. Phys. Chem. A 2008, DOI: 10.1021/jp71012b.

30. Bush, M. F.; Saykally, R. J.; Williams, E. R. Formation of Hydrated Triply Charged Metal Ions from Aqueous Solutions Using Nanodrop Mass Spectrometry. Int. J. Mass Spectrom. 2006, 253, 256-262.

31. Wong, R. L.; Paech, K.; Williams, E. R. Blackbody Infrared Radiative Dissociation at Low Temperature: Hydration of $\mathrm{X}^{2+}\left(\mathrm{H}_{2} \mathrm{O}\right)_{n}$, for $\mathrm{X}=\mathrm{Mg}$, Ca. Int. J. Mass Spectrom. 2004, 232, 59-66.

32. Senko, M. W.; Canterbury, J. D.; Guan, S. H.; Marshall, A. G. A High-Performance Modular Data System for Fourier Transform Ion Cyclotron Resonance Mass Spectrometry. Rapid Commun. Mass Spectrom. 1996, 10, 1839-1844.

33. Lioe, H.; O'Hair, R. A. J. Comparison of Collision-Induced Dissociation and Electron-Induced Dissociation of Singly Protonated Aromatic Amino Acids, Cystine and Related Simple Peptides Using a Hybrid Linear Ion Trap-FT-ICR Mass Spectrometer. Anal. Bioanal. Chem. 2007, 389, 1429-1437.

34. McFarland, M. A.; Chalmers, M. J.; Quinn, J. P.; Hendrickson, C. L.; Marshall, A. G. Evaluation and Optimization of Electron Capture Dissociation Efficiency in Fourier Transform Ion Cyclotron Resonance Mass Spectrometry. J. Am. Soc. Mass Spectrom. 2005, 16, 1060-1066.

35. Zubarev, R. A.; Horn, D. M.; Fridriksson, E. K.; Kelleher, N. L.; Kruger, N. A.; Lewis, M. A.; Carpenter, B. K.; McLafferty, F. W. Electron Capture Dissociation for Structural Characterization of Multiply Charged Protein Cations. Anal. Chem. 2000, 72, 563-573.
36. Chan, T. W. D.; Ip, W. H. H. Optimization of Experimental Parameters for Electron Capture Dissociation of Peptides in a Fourier Transform Mass Spectrometer. J. Am. Soc. Mass Spectrom. 2002, 13, 1396-1406.

37. Kjeldsen, F.; Haselmann, K. F.; Budnik, B. A.; Jensen, F.; Zubarev, R. A. Dissociative Capture of Hot (3-13 eV) Electrons by Polypeptide Polycations: An Efficient Process Accompanied by Secondary Fragmentation. Chem. Phys. Lett. 2002, 356, 201-206.

38. Adams, N. G.; Poterya, V.; Babcock, L. M. Electron Molecular Ion Recombination: Product Excitation and Fragmentation. Mass Spectrom. Rev. 2006, 25, 798-828.

39. Al Khalili, A.; Thomas, R.; Ehlerding, A.; Hellberg, F.; Geppert, W. D.; Zhaunerchyk, V.; af Ugglas, M.; Larsson, M.; Uggerud, E.; Vedde, J.; Adlhart, C.; Semaniak, J.; Kamińska, M.; Zubarev, R. A.; Kjeldsen, F.; Andersson, P. U.; Österdahl, F.; Bednarska, V. A.; Paal, A. Dissociative Recombination Cross Section and Branching Ratios of Protonated Dimethyl Disulfide and N-Methylacetamide. J. Chem. Phys. 2004, 121, $5700-5708$.

40. Neau, A.; Al Khalili, A.; Rosen, S.; Le Padellec, A.; Derkatch, A. M.; Shi, W.; Vikor, L.; Larsson, M.; Semaniak, J.; Thomas, R.; Någård, M. B.; Andersson, K.; Danared, H.; af Ugglas, M. Dissociative Recombination of $\mathrm{D}_{3} \mathrm{O}^{+}$and $\mathrm{H}_{3} \mathrm{O}^{+}$: Absolute Cross Sections and Branching Ratios. J. Chem. Phys. 2000, 113, 1762-1770.

41. Någård, M. B.; Pettersson, J. B. C.; Derkatch, A. M.; Al Khalili, A.; Neau, A.; Rosen, S.; Larsson, M.; Semaniak, J.; Danared, H.; Kallberg, A.; Österdahl, F.; af Ugglas, M. Dissociative Recombination of $\mathrm{D}^{+}\left(\mathrm{D}_{2} \mathrm{O}\right)_{2}$ Water Cluster Ions with Free Electrons. J. Chem. Phys. 2002, 117, 5264-5270.

42. Freiser, B. S.; Beauchamp, J. L. Electron-Impact Dissociation of Cyanobenzene Radical Cations by Ion-Cyclotron Resonance Spectroscopy. Chem. Phys. Lett. 1976, 42, 380-382.

43. Cody, R. B.; Freiser, B. S. Electron-Impact Excitation of Ions from Organics-An Alternative to Collision-Induced Dissociation. Anal. Chem. 1979, 51, 547-551.

44. Wang, B. H.; McLafferty, F. W. Electron-Impact Excitation of Ions from Larger Organic Molecules. Org. Mass Spectrom. 1990, 25, 554-556.

45. Jockusch, R. A.; Paech, K.; Williams, E. R. Energetics from Slow Infrared Multiphoton Dissociation of Biomolecules. J. Phys. Chem. A 2000, 104 3188-3196. 